\title{
A centralidade do coordenador pedagógico no trato com avaliações externas - o caso de Indaiatuba
}

Claudia Oliveira Pimenta

Mestra e doutoranda em

Educação pela Faculdade de

Educação da Universidade

de São Paulo (FE-USP) e

professora de História na rede

estadual de São Paulo.

E-mail:

pimentaclaudia@ibest.com.br
Resumo: 0 artigo discute a centralidade que coordenadores pedagógicos vêm adquirindo na articulação das avaliações externas para o exercício de sua função nas escolas municipais de Indaiatuba, corroborando estudos que tratam das atribuições destinadas à coordenação pedagógica. 0 texto é oriundo de pesquisa de mestrado finalizada em 2011 e que identificou a visão da gestão educacional do município quanto ao papel dos coordenadores no que se refere às avaliações, por meio da análise do Estatuto do Magistério e de entrevistas. Identificaram-se ações de formação desencadeadas pela rede, voltadas para os coordenadores com foco nas avaliações, bem como ações de monitoramento do trabalho do profissional. Ademais, detectaram-se opiniões dos próprios coordenadores pedagógicos sobre o tema, revelando influências importantes das avaliações em seu trabalho.

Palavras-chave: Coordenador pedagógico. Avaliações externas. Gestão pedagógica. 


\section{INTRODUÇÃO}

Entre os anos de 2009 e 2011, realizamos pesquisa de mestrado que teve como propósito analisar se e como as avaliações externas vêm influenciando o exercício da coordenação pedagógica nas escolas de ensino fundamental I da rede municipal de educação de Indaiatuba, explorando possíveis implicações para a gestão pedagógica do trabalho escolar.

No decorrer da pesquisa, a análise do Estatuto do Magistério do município e dos conteúdos das entrevistas fornecidas pela responsável pelo setor de Avaliação da Secretaria Municipal de Educação revelou a centralidade que os coordenadores pedagógicos vêm adquirindo, nesta rede, no que tange ao trato com as avaliações.

Além disso, em 2011, coletamos - por meio da aplicação de questionário - opiniões de 34 dos 44 coordenadores que atuam em 23 das 27 escolas que atendem ao ensino fundamental I. Dentre as questões respondidas por esses profissionais encontram-se aquelas referentes às suas atribuições, sua preparação para o trato com as avaliações e, ainda, indicações de como os mesmos vêm utilizando os materiais e resultados das provas.

Neste artigo, explicitaremos de que maneira os coordenadores pedagógicos vêm se tornando centrais na articulação dos processos avaliativos das escolas municipais de Indaiatuba. Para tanto, apresenta-se um breve histórico das avaliações externas no Brasil e sua relevância no debate relativo à melhoria da qualidade educacional, destacando possíveis implicações para a gestão escolar. Em seguida, apontamos como a rede municipal de educação de Indaiatuba se organiza para lidar com as avaliações e qual é o lugar dos coordenadores pedagógicos nesse processo. Ademais, apresentam-se estudos que tratam sobre a coordenação pedagógica no Brasil recente. Tais estudos vêm indicando que as avaliações têm sido, cada vez mais, incluídas no exercício da coordenação pedagógica. Por fim, traçamos algumas considerações.

\section{IMPLICAÇÕES DAS AVALIAÇÕES EXTERNAS PARA A GESTÃO ESCOLAR}

No Brasil, a prática da avaliação externa desenvolveu-se a partir dos anos 1980, inicialmente, no âmbito do Programa de Expansão e Melhoria do Ensino no Meio Rural do Nordeste Brasileiro - Edurural/NE, nos anos de 1981, 1983 e 1985. No período de 1987 a 1989, essas avaliações "estiveram associadas 
ao desenho e implantação de um 'sistema' de avaliação da educação básica que passou a ser conhecido, em 1991, como Sistema Nacional de Avaliação da Educação Básica - Saeb” (SOUSA, 2009, p. 33).

A implantação do Saeb insere-se no movimento da reforma educacional dos anos 1990 como parte da reforma do Estado cujas mudanças promoveram a ideia de que, para prestar serviços de melhor qualidade aos cidadãos, era necessário “enxugar” o Estado e torná-lo mais “eficiente” (BRESSER PEREIRA, 1998).

Ainda em meados da década de 1990, a exemplo da União, os estados passam a implementar iniciativas próprias de avaliação, evidenciando, segundo Sousa (2009, p. 36), “uma adesão à ideia da necessidade da avaliação para qualificar a gestão da educação”. Para a autora, tais avaliações aparecem como complemento àquelas realizadas em âmbito nacional, contudo, limitam-se a "informar os formuladores e implementadores de políticas, os profissionais das escolas e a sociedade em geral sobre o baixo rendimento dos alunos" (SOUSA, 2009, p. 39). É nesse contexto, segundo ela, que surgem propostas de utilização de incentivos "baseados nos resultados da avaliação", com a expectativa de que tais resultados sejam utilizados para implementar ações de melhoria da aprendizagem, revelando, desse modo, o "fraco" poder de indução das avaliações.

Nos anos 2000, detecta-se a concepção e efetivação de avaliações externas municipais bastante semelhantes àquelas produzidas em âmbito estadual e federal, com foco principal das proficiências de Língua Portuguesa e Matemática (OVANDO, 2011; FERRAROTO, 2011). Ressalte-se que, no município de Indaiatuba - foco de nosso estudo - desde 2008 é elaborada e aplicada a Avaliação Municipal do Desempenho do Aluno (Amda), cujo foco também recai sobre as mesmas proficiências.

Notadamente, tais movimentos evidenciam que a prática da avaliação externa vem se intensificando no Brasil, sendo possível afirmar a existência de um entendimento generalizado de que a avaliação se configura como instrumento importante na construção e reflexão sobre o processo educacional e sua gestão.

Cabe destacar outro aspecto fundamental desse movimento: a centralidade das avaliações no debate sobre a qualidade da/na educação. A universalização do acesso como um primeiro passo para a garantia da qualidade evidenciou, entre outras questões, a incapacidade de nossas escolas em lidar com a 
diversidade de alunos oriundos de camadas mais pobres da população e com necessidades de apoio para sua aprendizagem que não se restringem aos tradicionais programas de ensino. Essa incapacidade - traduzida nos persistentes índices de repetência escolar - tem sido alvo de críticas no país muito antes da implementação das avaliações externas.

No início da década de 1990, Ribeiro (1991, p. 15) criticava o que, segundo ele, sugere a cultura pedagógica brasileira “de que repetir ajuda a criança a progredir em seus estudos". Para o autor, havia uma preocupação com a frequência dos alunos na escola, mas não necessariamente com "a qualidade da educação recebida” (RIBEIRO, 1991, p. 19). Já naquele momento, o autor sugeria que uma possibilidade de alavancar a busca pela qualidade do ensino seria "a montagem de um sistema de avaliação cognitiva dos alunos que desse ao público instrumentos de cobrança da qualidade da escola" (RIBEIRO, 1991, p. 19), contribuindo para uma universalização competente do ensino fundamental.

Ao encontro com as preocupações de Ribeiro, as primeiras ações desencadeadas para viabilizar um sistema de avaliação nacional, de acordo com Bonamino e Franco (1999, p. 108), apareciam no cenário educacional brasileiro com o propósito de "verificar não apenas a cobertura do atendimento educacional oferecido à população, mas, principalmente, o desempenho dos alunos dentro do sistema”. Essas ações, segundo os autores, "levaram à subsequente institucionalização do Saeb"1.

De acordo com Vianna (2003, p. 8), a utilização da avaliação educacional no Brasil, em especial a partir dos anos 1990, representa uma

\section{[...] tentativa de encontrar um caminho para a solução de alguns problemas educacionais mais prementes, esperando, possivelmente, que os processos avaliativos determinariam, entre outros resultados, a elevação dos padrões de desempenho, caso fossem conduzidos com o uso de tecnologias testadas na sua eficiência em outras experiências semelhantes, realizadas em diversos países, ainda que com culturas diferentes.}

As iniciativas de avaliação dos sistemas de ensino, de acordo com Sousa (2009, p. 32), têm sido disseminadas à sociedade "[...] como mecanismos voltados a subsidiar a elaboração de diagnósticos sobre a realidade educacional e a orientar a formulação de políticas visando à promoção da equidade e da melhoria da qualidade do ensino".

O Saeb foi criado em 1988 e implantado em 1990 pelo governo federal. Disponível em: 〈http://www.inep.gov.br/saeb〉. Acesso em: 23 mar. 2011. 
Contudo, ainda em relação ao Saeb, pesquisadores têm alertado que as avaliações vêm se constituindo em importantes instrumentos de gestão e controle por parte dos gestores e órgãos governamentais. Para Sousa e Oliveira (2003, p. 881),

\begin{abstract}
O delineamento assumido pelo Saeb encontra respaldo em argumentos que se alinham na direção de justificar a avaliação como instrumento de gestão educacional, tais como: possibilidade de compreender e intervir na realidade educacional, necessidade de controle de resultados pelo Estado, estabelecimento de parâmetros para comparação e classificação de desempenhos, estímulo por meio da premiação, possibilidade de controle público do desempenho do sistema escolar.
\end{abstract}

O debate sobre o conceito de qualidade na educação, em grande parte, advém do "mundo dos negócios" e não existe consenso mesmo entre seus integrantes. Sousa (1997, p. 26) assevera que “[...] qualidade não é 'algo' dado, não existe 'em si', remetendo à questão axiológica, ou seja, dos valores de quem produz a análise de qualidade" e, portanto, os critérios utilizados para a definição do que é qualidade estão intrinsecamente vinculados aos valores de quem os concebe.

O Plano de Desenvolvimento da Educação (PDE), lançado em 2007 pelo governo federal, estabeleceu metas para a educação básica. De acordo com seus implementadores, tais metas contribuem para viabilizar um atendimento de qualidade aos alunos tanto por parte das escolas quanto das secretarias de educação, advertindo que, para identificar as escolas que apresentam baixo desempenho escolar, o plano dispõe do Índice de Desenvolvimento da Educação Básica (Ideb), que é calculado tomando por base os dados de aprovação escolar e as médias de desempenho no Saeb (para os estados e para o país) e da Prova Brasil (para os municípios) ${ }^{2}$, criado em 2007 pelo Instituto Nacional de Estudos e Pesquisas Educacionais Anísio Teixeira (Inep) e que "pretende ser o termômetro da qualidade da educação básica em todos os estados, municípios e escolas do Brasil” (BRASIL, 2008, p. 4).

É nesse cenário que o debate sobre o papel da escola e de seus profissionais em prol da melhoria da qualidade do processo educacional tem adquirido relevância. Atualmente, a gestão escolar vem sendo desafiada a organizar o trabalho da escola tendo como base, entre outros indicadores, os resultados aferidos por avaliações externas e, não raro, tais resultados têm sido

Disponível em: 〈http://portal.inep.gov.br/web/portal-ideb/o-que-e-o-ideb〉. Acesso em: 2 fev. 2013. 
vinculados a mecanismos de responsabilização que se configuram como uma das facetas indutoras do trabalho escolar, especialmente do trabalho pedagógico.

A implantação da Prova Brasil, em 2005, e do Ideb, em 2007, intensificou o uso de resultados das avaliações por escolas e redes de ensino. Essa intensificação parece relacionar-se com a vinculação dos resultados obtidos no índice a financiamento promovido pelo governo federal, via PDE, para escolas e municípios com baixo desempenho. Soma-se a isso a divulgação dos resultados pelo governo federal e pela mídia e que tem ensejado um clima de disputa entre as redes e escolas para atingir as metas estabelecidas pelo Ideb, impulsionando as gestões escolares a organizarem o trabalho escolar em conformidade com as avaliações (SOUSA; OLIVEIRA, 2003; ARCAS, 2009; SOUSA, 2009; SILVA, 2011).

De outro lado, a incorporação dos dados produzidos pelas avaliações às ações da escola, em certa medida, também pode significar uma contribuição importante para a reflexão sobre o fazer pedagógico (OLIVEIRA, 2008; ESQUINSANI, 2010). Consideramos que as avaliações externas podem ser úteis para um maior aprimoramento do trabalho escolar, desde que entendidas como constitutivas da prática pedagógica e não como único instrumento para garantir a qualidade do processo educacional.

Na rede municipal de educação de Indaiatuba, as avaliações externas têm-se configurado como elemento importante da política educacional e provocado efeitos no trabalho da escola e da gestão escolar, especialmente da gestão pedagógica, tornando singular o papel do coordenador pedagógico. Destaquese que esta rede possui características peculiares em relação às avaliações, sobre as quais discorremos a seguir.

A ORGANIZAÇÃO E ARTICULAÇÃO DAS AVALIAÇÕES EXTERNAS NA REDE MUNICIPAL DE EDUCAÇÃO DE INDAIATUBA

Indaiatuba atende à educação infantil e ao ensino fundamental I. Apresenta algumas peculiaridades quanto às avaliações externas, quais sejam: possui um setor específico - na Secretaria - para organizar e operacionalizar as avaliações sistêmicas; utiliza a Prova Brasil e a Provinha Brasil desde 2007; em 2008, criou sua própria avaliação externa - a Avaliação do Desempenho do Aluno (Amda) - elaborada e aplicada pelo Setor de Avaliação da Secretaria; e aderiu ao Sistema de Avaliação do Rendimento Escolar do Estado de São Paulo (Saresp) em 2010. 
Além de elaborar a Amda, o Setor de Avaliação, de acordo com a responsável pela área, acompanha a execução das avaliações externas conduzidas pelo Estado e pela União, nas escolas da rede municipal. A Amda é aplicada aos alunos de todos os anos/séries do ensino fundamental I, três vezes ao ano: "no início, com finalidade diagnóstica; no fim do 1 ํㅡㄴ semestre, para detectar os avanços obtidos, e no fim do ano, para verificar onde os alunos conseguiram chegar”. Segundo a entrevistada, os resultados das provas são utilizados para a consecução do planejamento e para a organização das capacitações dos coordenadores e diretores escolares.

Após a aplicação das provas, os gestores escolares - em conjunto com os professores - fazem o levantamento dos pontos positivos e negativos do instrumento aplicado. A síntese é enviada ao Setor de Avaliação, que filtra as informações e busca contemplar, nos instrumentos seguintes, as considerações da escola. Após a correção, o setor envia as provas para unidades escolares e os professores podem realizar a revisão da correção. 0 resultado só é divulgado após esse processo. Esse movimento parece legitimar a Amda junto aos profissionais das escolas. Vale destacar que essa ação não ocorre em relação à Prova Brasil e ao Saresp, revelando que a Amda possui um grau de exterioridade menor que as avaliações advindas dos governos federal e estadual, cujas avaliações são elaboradas, aplicadas e corrigidas por agentes externos à escola, não permitindo a participação dos sujeitos que nela atuam.

Os professores utilizam, ainda, avaliações e sondagens organizadas por eles próprios, para suas turmas e, de acordo com a responsável pelo Setor de Avaliação, a Secretaria busca efetivar ações para auxiliar as escolas na articulação da avaliação externa com a avaliação da aprendizagem. Para Nevo (2002, p. 6, tradução nossa), a avaliação externa cumpre papel distinto daquele exercido pela avaliação interna, porém, são complementares entre si. Em suas palavras:

Embora a avaliação interna geralmente tenha a vantagem de ser mais sensivel ao contexto local das escolas e suas características únicas, podem sofrer de uma perspectiva estreita em suas qualidades gerais. A avaliação externa pode adicionar pontos em comum para a singularidade da escola e também fornecer uma base para julgar suas qualidades.

Desse modo, o cotejamento dos resultados de avaliações externas e internas parece ter potencial para auxiliar no aprimoramento do trabalho pedagógico. Contudo, é preciso cuidar para que as avaliações internas das escolas não se conformem às avaliações externas, reproduzindo suas características 
e objetivos e, por conseguinte, limitando o currículo, dado que, no Brasil, as avaliações externas têm seu foco principal restrito a determinadas proficiências, competências e habilidades e pode induzir as escolas a aprofundar suas ações em função dessas características em detrimento das demais áreas do conhecimento. Cabe ressaltar que a entrevistada não informou de que forma ocorre o cotejamento entre os resultados de ambos os tipos de avaliação.

Para além desses instrumentos avaliativos, a rede municipal de Indaiatuba ainda adota um Plano de Ação (baseado no PDE) que é organizado conjuntamente pelas escolas e conta com a participação dos professores e da orientação pedagógica da Secretaria. Segundo a responsável pelo Setor de Avaliação, esse instrumento colabora para o acompanhamento e a avaliação das ações pedagógicas das escolas, por parte da orientação pedagógica e por um supervisor de ensino que, juntos, analisam e supervisionam os processos de aprendizagem dos alunos, por meio da Amda e do Plano de Ação.

Apesar da existência de instrumentos diferenciados para a avaliação e o acompanhamento da aprendizagem dos alunos, em Indaiatuba observa-se que as avaliações externas, especialmente a Amda, parecem ter adquirido centralidade nesses processos. Destaque-se que, no ano em que ocorre a Prova Brasil (a cada dois anos), o município chega a utilizar sete instrumentos de avaliação que não são elaborados pelos professores das escolas, quais sejam: a Amda (três vezes); a Provinha Brasil (duas vezes - semestral); a Prova Brasil (uma vez) e o Saresp (uma vez).

Outra característica da rede municipal de Indaiatuba que sugere relações com as avaliações externas é o uso do mesmo material didático em todas as escolas da rede. O material, outrora concebido pela própria Secretaria, passou, em 2011, a ser elaborado por empresa contratada. Nas palavras da responsável pelo Setor de Avaliação, no material “[...] existem alguns exercícios, que elas [professoras] até brincam e chamam de Amdinha, algumas atividades que reportam à avaliação que nós fazemos na rede”. Tal afirmação parece indicar uma forte relação entre currículo e avaliação, haja vista a utilização de exercícios propostos no material didático adotado na elaboração da avaliação do município.

Indaiatuba possui, ainda, um sistema de bonificação docente atrelado aos resultados da Amda e do Ideb, denominado Gratificação por Produção e Aperfeiçoamento Profissional (GPAP), que foi regulamentado pelo Decreto $\mathrm{n}$ 은 9.724, de 28 de março de 2008. Para além do desempenho dos estudantes 
nas avaliações, o sistema também leva em consideração a assiduidade dos profissionais da educação e os cursos de capacitação que estes frequentam. Quanto aos gestores escolares, o recebimento do bônus está condicionado ao resultado alcançado pela escola como um todo. Para a gestão da Secretaria, tais políticas contribuem para estimular melhorias no processo educacional.

Essa expectativa corrobora as apreciações de Sousa (2009) quanto ao uso de incentivos vinculados às avaliações, já mencionadas neste texto. No caso de Indaiatuba, ao que tudo indica, essa tendência tem sido ampliada e intensificada e é nesse contexto que os coordenadores pedagógicos adquirem relevância na gestão e articulação das ações pedagógicas das escolas da rede.

\section{OS COORDENADORES PEDAGÓgICOS E AS AVALIAÇÕES}

Diante da proeminência das avaliações externas no Brasil nas últimas décadas, partimos da suposição de que tais avaliações têm suscitado mudanças nas ações de natureza pedagógica e administrativa sob responsabilidade do coordenador pedagógico. No município de Indaiatuba, tal premissa tem assento no papel e nas atribuições destinadas a esse profissional e se revela nos depoimentos dos coordenadores que responderam à nossa pesquisa. A ele é conferida a responsabilidade de garantir a qualidade do ensino, de acordo com o Estatuto do Magistério vigente ${ }^{3}$.

\footnotetext{
I - Professor Coordenador: é o profissional que desempenhará a função de assistência 4 pedagógica e administrativa visando assegurar o funcionamento e a qualidade do ensino, na Unidade Escolar em que estiver sediado.
}

Destaca-se que essa atribuição não é destinada, neste documento, aos demais profissionais que exercem funções gestoras, a saber:

\footnotetext{
II - Professor Gestor: profissional que desempenhará a função administrativa e gerencial da Unidade Escolar, respondendo por ela e representando-a interna e externamente, inclusive nos programas desenvolvidos pela Secretaria Municipal de Educação.
}

III - Professor Orientador Pedagógico: profissional que elaborará, planejará e orientará as diretrizes pedagógicas da educação municipal de acordo com as políticas da Rede de Ensino Público Municipal.

Lei Complementar no 7, de 5 de janeiro de 2009, capítulo VI, seção II, artigo 15, item 1. 4 Em Indaiatuba não existem os cargos de coordenador pedagógico, diretor ou orientador pedagógico, ou seja, todos são professores e podem exercer funções "gestoras" após três anos de atuação em sala de aula. 
Questionada sobre a vinculação do papel do coordenador pedagógico à garantia da qualidade de ensino, prevista no Estatuto, a responsável pelo Setor de Avaliação da Secretaria asseverou que a escola pode realizar um bom trabalho com base nos dados das avaliações desde que o coordenador promova essa articulação. Em suas palavras,

Agora, porém, as avaliações externas, tanto do governo federal quanto do estado ou do próprio município, trazem indicadores reais e dá para a escola fazer um trabalho muito bom em cima disso, desde que o coordenador faça essa articulação, porque senão [...]

Ainda de acordo com a entrevistada, as expectativas do Setor de Avaliação da Secretaria quanto ao papel dos coordenadores no desenvolvimento das ações pedagógicas da escola na relação com as avaliações e seus resultados são de que

[...] eles consigam levar isso aos professores em relação à construção de ações de acordo com os indicadores, porque os indicadores trazem, nos dizem muita coisa; e de que eles [coordenadores] consigam criar, planejar em cima disso, nortear a prática pedagógica em cima desses resultados [das avaliações].

O coordenador pedagógico tem sido visto, em boa parte das redes de ensino, como um profissional singular e de fundamental importância para a articulação das ações pedagógicas e formativas da escola. De acordo com o relatório intitulado 0 Coordenador Pedagógico e a Formação de Professores: Intenções, Tensões e Contradições, resultante de pesquisa desenvolvida pela Fundação Carlos Chagas (FCC) e encomendada pela Fundação Victor Civita, “há o consenso, dentro e fora do Brasil, quanto à importância da coordenação/ orientação pedagógica para o contexto escolar, mesmo quando ela não é feita por um profissional em cada escola" (FCC; FVC, 2011, p. 10).

No Brasil, segundo o relatório, a pesquisa atesta um crescente interesse em relação “[...] à questão da profissão, da identidade profissional e carreira" (FCC; FVC, 2011, p. 14) do coordenador pedagógico.

Na pesquisa supracitada foram analisados "textos publicados em coletâneas" dirigidas aos coordenadores pedagógicos, “[...] cujo caráter se aproxima mais de reflexões sobre práticas ou concepções” (FCC; FVC, 2011, p. 14) e teses/ dissertações. 0 relatório afirma que nos textos aparece, de forma recorrente, a ideia de que a principal função do coordenador "é a formação continuada dos professores" (FCC; FVC, 2011, p. 18) e sugerem que as atribuições do coordenador, no que se refere à dimensão formativa, se fundamentam em: promover a articulação da equipe escolar para elaborar o projeto político- 
pedagógico da escola, mediar as relações interpessoais, planejar, organizar e conduzir as reuniões pedagógicas, enfrentar as relações de poder desencadeadas na escola, desempenhar sua prática atendendo à diversidade dos professores e das escolas, efetivar o registro escrito como forma de sustentar a autoria de seu papel na escola (FCC; FVC, 2011, p. 18).

Com referência às teses e dissertações, o estudo revelou um "grande número de pesquisas sobre a coordenação pedagógica e seu aumento nos anos recentes", indicando “[...] certo consenso sobre a importância desse profissional nas escolas, por um lado, e a necessidade de compreender suas atribuições e práticas e, ao mesmo tempo, fundamentar princípios para suas ações” (FCC; FVC, 2011, p. 21). Na maioria dessas produções, “[...] os temas, objetivos e questões investigadas” giram em torno de três eixos: “[...] articulação dos processos pedagógicos e educativos, transformação das condições pedagógicas e de ensino; e formação de professores" (FCC; FVC, 2011, p. 21).

Ao analisar as atribuições previstas para os coordenadores pedagógicos nas cinco regiões brasileiras, a pesquisa detectou:

\begin{abstract}
[...] atividades como avaliação dos resultados dos alunos da escola, diagnóstico da situação de ensino e aprendizagem, supervisão e organização das ações pedagógicas cotidianas (frequência de alunos e professores), andamento do planejamento de aulas (conteúdos ensinados), planejamento das avaliações, organização de conselhos de classe, organização das avaliações feitas pelos sistemas de ensino (municipal, estadual ou nacional), material necessário para as aulas e reuniões pedagógicas, atendimento de pais etc., além da formação continuada dos professores (FCC; FVC, 2011, p. 33).
\end{abstract}

Para Esquinsani (2010, p. 134), os coordenadores pedagógicos têm, entre outras funções, o papel de organizar os documentos da escola, especialmente os que se referem ao trabalho pedagógico. Nesse aspecto, compreende que os dados produzidos pelas avaliações externas "podem ser incorporados aos documentos escolares (o que implica planejamento e significação dos mesmos)" e vê "a atuação do coordenador pedagógico", como mediadora "deste processo".

\footnotetext{
[...] o coordenador pedagógico atua como mediador e assessor no planejamento, acompanhamento e orientação acerca dos processos de aprendizagem internos e, por consequência, dos processos internos e externos de avaliação educacional. Em ambos os casos, o retorno dos resultados (produtos) dos processos avaliativos apresenta indicativos para o trabalho de planejamento escolar no que tange a temas como: currículo, objetivos, habilidades, competências esperadas de anos, séries ou turmas e o cumprimento das diretrizes da Proposta Pedagógica e seus respectivos desdobramentos (ESQUINSANI, 2010, p. 141).
} 
Para a autora, cabe ao coordenador "organizar a escola a partir das informações obtidas” por meio das avaliações, dando significado à realização das mesmas e "incorporando os dados obtidos a tomadas de decisão que afetam a parte documental da escola [...]". Como exemplo, cita a proposição de alterações no Regimento Escolar quanto à "média anual" ou "procedimentos de recuperação" nele previstos, e ainda a discussão e "alteração dos planos de estudo da escola em relação a algum componente curricular" (ESQUINSANI, 2010, p. 141). Para ela, o coordenador pode atuar também na dinamização “das políticas educacionais no interior da escola” (ESQUINSANI, 2010, p. 142) e, nesse sentido, deve articular

[...] a comunidade escolar aos demais setores de redes e sistemas de ensino, visando ao aperfeiçoamento da gestão pedagógica e administrativa e ao fortalecimento dos canais de participação, responsabilização e comprometimento da comunidade escolar

(ESQUINSANI, 2010, p. 142).

A autora acredita, ainda, que o papel do coordenador em relação às avaliações pode tanto "regular" quanto "emancipar" as ações da escola.

Se reguladora, a função do coordenador cobrará resultados de acordo com a lógica do mercado e de aferição dos resultados, tal qual o esperado pelo Estado avaliador [...] se emancipadora, a atuação do coordenador pedagógico assumirá um espaço de organização dos elementos dispostos ao trabalho docente no interior das escolas, mediando a dimensão administrativa (documentos), a dimensão pedagógica e a dimensão política (ESQUINSANI,

No documento “A gestão pedagógica e o desempenho escolar”, produzido em 2005 pela Secretaria da Educação do Governo do Estado do Ceará, sublinhase que "o papel formador do coordenador pedagógico deve estar voltado para a orientação, o gerenciamento e a observância dos produtos, quer do cotidiano da escola, quer dos resultados das avaliações de sistema”. Contudo, considera-se que "esse trabalho torna-se difícil porque se constitui [em] uma prática nova para a escola, para a qual muitos coordenadores pedagógicos não se sentem preparados" (SEE/CE, 2005, p. 9).

A "novidade" das avaliações externas reside no fato de que, apesar de se fazerem presentes no cenário educacional brasileiro há mais de duas décadas, seu uso pelas escolas e profissionais é recente. Além disso, a dinâmica escolar nem sempre favorece a imersão necessária do coordenador nas questões pedagógicas, pois este, muitas vezes, é impelido a incumbirse de outras tarefas - também urgentes à escola, mas não necessariamente relativas ao seu trabalho. Soma-se a isso o não entendimento, da escola e/ou dele próprio, da delimitação de suas atribuições. 
Todavia, é possível dizer que, na maioria das redes de ensino, este profissional é tido como o principal responsável pelo monitoramento e articulação das ações pedagógicas da escola, organizando, acompanhando e discutindo com os demais segmentos, especialmente com os professores, os processos de ensino e de aprendizagem. Ademais, usualmente, tem se responsabilizado pela organização dos processos avaliativos internos da escola e, mais recentemente, dos externos - mesmo com as limitações expostas anteriormente.

Em Indaiatuba, os coordenadores pedagógicos que responderam à nossa pesquisa forneceram informações abrangentes quanto às suas atribuições. Como dito anteriormente, os resultados referem-se às respostas de 34 dos 44 coordenadores que atuam em 23 das 27 escolas que atendem ao ensino fundamental I na rede municipal de educação. Informamos que essa questão era aberta e, portanto, os respondentes podiam mencionar várias atribuições ou nenhuma. A priorização de atendimento das demandas relativas às questões pedagógicas foram as mais indicadas, sendo que a prestação de assistência aos professores, a garantia de aprendizado dos alunos e a coordenação da elaboração/execução do projeto pedagógico e planos de aula concentram o maior número de indicações - 27, 21 e 19, respectivamente.

Perguntados sobre as contribuições de sua formação inicial para lidar com a Avaliação de sistemas de desempenho e avaliação institucional (que engloba as avaliações externas), 38\% das indicações dos coordenadores apontaram que a formação acadêmica foi insuficiente para o exercício das atividades e $35 \%$ afirmaram que esse assunto não foi abordado. Esse resultado expressa o fato de que tais avaliações são recentes e eram pouco difundidas em graduações mais antigas.

Entretanto, e talvez por isso, identificam-se investimentos na formação dos coordenadores - no que se refere às avaliações - por parte da Secretaria Municipal de Educação. A responsável pelo Setor de Avaliação informou que, a partir de 2011, os coordenadores pedagógicos passaram a ser o foco das capacitações para o trabalho com as avaliações externas. Quando perguntados sobre sua participação em cursos de capacitação sobre avaliações externas e índices correlatos, oferecidos pela Secretaria, 26 dos 34 respondentes afirmaram ter participado dos cursos. Quanto aos temas tratados, a Amda obteve 22 menções; a Prova Brasil, 19; e o Saresp, 17. Dos índices, o Ideb recebeu o maior número de apontamentos: 12.

Os coordenadores ainda participam de outros cursos oferecidos tanto pela 
Secretaria quanto pelo Ministério da Educação (MEC). Dos 34 respondentes da pesquisa, 30 indicaram cursos dos quais participaram, sendo 14 indicações para cursos direcionados à leitura e à escrita; nove para a matemática; nove para a área de informática; 16 para trabalho pedagógico; e 14 para outros cursos com características mais pontuais. O número de indicações para os cursos voltados para as disciplinas de Língua Portuguesa e Matemática parece relacionar-se com as avaliações, dado que tais disciplinas constituemse no principal foco das provas. Já as indicações dos cursos voltados para o exercício da coordenação pedagógica sugerem a preocupação, por parte da Secretaria, com a formação desse profissional.

No que tange ao uso dos materiais e resultados das avaliações no exercício da coordenação pedagógica, 33 respondentes afirmaram utilizá-los. A forma de uso mais citada foi orientar professores para o desenvolvimento de atividades voltadas para a superação das dificuldades apresentadas pelos alunos, que recebeu 29 apontamentos.

Perguntados explicitamente sobre eventuais influências das avaliações no exercício de sua função, 33 coordenadores responderam positivamente: 22 sinalizaram a utilização das avaliações para organizar a orientação aos professores em função dos resultados dos alunos nas provas; dez afirmaram desenvolver estudos/pesquisas para orientar professores; cinco para orientar professores com foco nos descritores das provas e nos Parâmetros Curriculares Nacionais (PCNs) e quatro para orientar professores visando reflexão sobre a prática pedagógica. Quase a totalidade dos coordenadores pedagógicos manifesta uma apreciação positiva sobre a influência das avaliações externas na organização de seu trabalho. Entretanto, há que se ponderar que um respondente mencionou outra perspectiva, ou seja, que a avaliação dificulta o seu trabalho "porque gera angústias nos professores e quebra a organização da escola".

Quanto às contribuições das avaliações para o exercício da coordenação pedagógica, 29 coordenadores fizeram indicações. Paras as dificuldades, houve 21 apontamentos.

No que tange às contribuições, identificamos quatro grandes movimentos. 0 primeiro deles é o estímulo para a organização de um plano de ação, o qual reorienta o trabalho pedagógico e norteia o trabalho dos coordenadores para planejar ações, orientar professores e traçar metas (13 indicações). 0 segundo é a função diagnóstica da avaliação que, segundo eles, ajuda a identificar as dificuldades dos alunos e dos professores, as falhas no planejamento 
docente e no planejamento da escola (11 indicações). 0 terceiro movimento refere-se ao monitoramento da aprendizagem dos alunos, do trabalho dos professores, do coordenador e da escola (11 indicações). Por fim, houve duas indicações afirmando que a avaliação motiva a atuação do corpo docente e do coordenador.

Em relação às dificuldades, houve oito apontamentos para dificuldades de cunho atitudinal, relacionadas à resistência dos professores às avaliações, ao desinteresse de alunos e professores e ao pouco envolvimento das famílias no debate sobre elas; seis menções destacam dificuldades de cunho operacional, ou seja, a organização da aplicação das provas e sua correção, questões relativas à frequência dos alunos no dia da prova e o fato de o aluno evadido, segundo os respondentes, ser considerado faltante no cômputo geral; outras seis indicações estão associadas a dificuldades de ordem técnica para combinar conteúdos propostos pela rede com os conteúdos das avaliações externas e o fato de estas serem elaboradas com um único parâmetro. Por fim, cinco indicações são relacionadas às dificuldades de uso das avaliações e seus resultados em prol da reflexão sobre a prática pedagógica, a não incorporação dos resultados como algo contínuo nos planejamentos e planos de aula, além do pouco envolvimento e mobilização dos professores.

De acordo com a responsável pelo Setor de Avaliação da Secretaria, as dificuldades dos coordenadores para lidar com as avaliações externas estão ligadas à polêmica inerente aos processos avaliativos e ao entendimento, por parte desses, de que a padronização das avaliações não atende às especificidades de cada escola. Contudo, considera que os coordenadores têm conseguido lidar com os resultados das avaliações e assinalou que o fato de muitos terem assumido recentemente a função (à época da entrevista - agosto de 2011 -, 68\% dos respondentes possuíam menos de um ano como coordenadores) é uma justificativa relevante para o investimento na capacitação desses profissionais para trabalhar com as avaliações. Informou que a orientação pedagógica da Secretaria conduziu uma pesquisa, junto aos coordenadores, para indagá-los sobre as dificuldades enfrentadas no trabalho nas escolas. Os obstáculos mais apontados, segundo ela, referemse à “avaliação, aos descritores e como trabalhar o resultado".

Contudo, a entrevistada constata que os coordenadores, apesar das dificuldades, têm conseguido lidar com os resultados das avaliações. Para ela, os pedidos de ajuda cada vez mais frequentes à Secretaria representam um indicador positivo da compreensão desses profissionais sobre a importância de trabalhar com os resultados. 
Todavia, observa-se que o número de menções a contribuições das avaliações externas para o exercício da coordenação pedagógica é superior ao número de dificuldades apontadas pelos respondentes, o que leva a crer que os coordenadores pedagógicos vêm considerando as avaliações externas como um instrumento capaz de subsidiar e aprimorar o seu trabalho. Ainda assim, vale informar que para alguns coordenadores que responderam à nossa pesquisa, as avaliações externas não devem representar a única estratégia para propiciar o sucesso escolar.

A análise dos dados indica um uso cada vez mais frequente das avaliações externas e seus resultados, por parte dos coordenadores pedagógicos do ensino fundamental I da rede municipal de educação de Indaiatuba. Se por um lado parte desses profissionais reconhece os limites das avaliações, a maioria as define como instrumentos importantes para a organização de seu trabalho e da gestão pedagógica das escolas em que atuam.

Não podemos inferir que todos os coordenadores da rede municipal de Indaiatuba são influenciados pelas avaliações externas na consecução de seu trabalho, dado que não consultamos a totalidade desses profissionais. Mas podemos dizer que há uma tendência de intensificação do uso das avaliações na composição do trabalho escolar e que estas têm implicações, explicitadas nos depoimentos coletados, na organização do trabalho dos coordenadores e das escolas. Ademais, identificam-se ações desencadeadas pela Secretaria Municipal de Educação voltadas para a formação e capacitação desses profissionais no que se refere a conteúdos e formas de articulação, no âmbito escolar, das informações fornecidas pelas avaliações, visando à melhoria do desempenho das crianças. Agrega-se a isso, como já mencionado neste texto, o entendimento por parte da Gestão da Secretaria de que os coordenadores são peça-chave para o trabalho com as avaliações, explicitados tanto na fala da responsável pelo Setor de Avaliação quanto no Estatuto do Magistério que vincula o papel do coordenador à garantia da qualidade educacional, qualidade essa - atualmente - entendida como resultados mensurados nas avaliações externas.

\section{ALGUMAS CONSIDERAÇÕES}

Este artigo se propôs a debater a relevância do papel dos coordenadores pedagógicos no trato com as avaliações externas na rede municipal de educação de Indaiatuba. De acordo com alguns estudos aqui apresentados e que tratam das atribuições dos coordenadores pedagógicos no Brasil, 
os materiais e resultados produzidos por essas avaliações vêm sendo incorporados - nos últimos anos - ao trabalho dos coordenadores que, comumente - entre outras demandas - possuem a tarefa de acompanhar e articular os processos avaliativos das escolas, sejam estes internos ou externos a ela. Ao que tudo indica, o que vem ocorrendo em Indaiatuba não se restringe apenas a esse município, ao contrário, parece corroborar o que vem sendo identificado pelos estudos.

Indaiatuba possui singularidades em relação às avaliações: setor próprio para cuidar das avaliações sistêmicas; elaboração de instrumento próprio de avaliação, com relativa participação dos profissionais das escolas nas decisões quanto aos resultados e formulação de itens; mecanismos de formação com foco nas avaliações, voltados principalmente para os coordenadores pedagógicos; avaliação de desempenho dos profissionais da rede vinculada a incentivos financeiros; elaboração de currículo unificado e uso de material didático, produzido por empresa contratada, que parecem atender às especificações e aos conteúdos das provas. Tais características não podem ser generalizadas para outras redes. Ainda assim, ao revelar um movimento para fortalecer a utilização das avaliações externas em sua rede, Indaiatuba dá mostras de acompanhar a tendência que atualmente se coloca para o restante do país no que diz respeito ao trato com as avaliações.

A centralidade das avaliações externas no debate sobre qualidade educacional, nas últimas décadas, parece induzir a práticas no interior das redes de ensino com vistas à responsabilização das diversas instâncias, especialmente as escolas, pelos resultados obtidos nas provas. 0 atrelamento dos resultados obtidos a incentivos financeiros para os profissionais da educação tem sido visto como capaz de promover ações nas escolas voltadas para a garantia da melhoria no desempenho dos alunos. Em Indaiatuba, essa vinculação ocorre por meio da GPAP, que leva em consideração os resultados dos alunos e escolas na Amda e no Ideb.

A partir da implementação da Prova Brasil e do Ideb, em meados dos anos 2000, identifica-se o uso dos materiais e resultados produzidos pelas avaliações por escolas e municípios com implicações para a organização do trabalho escolar e, consequentemente, para o trabalho de seus profissionais. Em Indaiatuba, tais implicações foram evidenciadas em nosso estudo e explicitadas neste texto.

A utilização dos resultados das provas como elementos importantes na consecução do planejamento do trabalho pedagógico das escolas é 
considerada, em Indaiatuba, como uma das principais atribuições dos coordenadores. Nesse sentido, há investimentos por parte da Secretaria Municipal de Educação na formação desses profissionais no que se refere às avaliações, com especial atenção para a avaliação organizada no âmbito do município, bem como sobre os materiais didáticos que expressam o currículo da rede e para o exercício da coordenação pedagógica.

As informações fornecidas pela responsável pelo Setor de Avaliação da Secretaria, bem como aquelas expressas no Estatuto do Magistério de Indaiatuba conferem aos coordenadores o papel de garantir a qualidade do processo educacional. Essa atribuição aos coordenadores pedagógicos, em Indaiatuba, parece indicar que as mesmas devem ser contempladas no exercício da coordenação pedagógica das escolas, corroborando os estudos e pesquisas que assinalam a centralidade adquirida pelas avaliações externas no debate sobre a melhoria da qualidade educacional brasileira.

Na opinião da maioria dos coordenadores que responderam à nossa pesquisa, as avaliações são um elemento positivo e fundamental para se planejar as ações pedagógicas. Eles afirmaram utilizar as avaliações, principalmente, para orientar o trabalho dos professores com o objetivo de diminuir as dificuldades de aprendizagem dos alunos, para pensar estratégias de melhoria de seu desempenho e para refletir sobre o seu próprio trabalho.

Os coordenadores citaram contribuições significativas das avaliações para 0 exercício da coordenação pedagógica nas escolas em que atuam, com ênfase na reorientação do trabalho pedagógico, no planejamento de ações, na orientação dos professores e para traçar metas. Contudo, alguns enfatizaram que as avaliações externas não devem ser consideradas como a única estratégia para proporcionar o sucesso escolar.

Em relação às dificuldades para lidar com as avaliações no interior das escolas, os coordenadores apontaram, entre outras questões, o não entendimento dos materiais e resultados e a resistência de parte dos professores para trabalhar com as avaliações, cujo motivo principal está na vinculação dos resultados à bonificação docente. Ainda assim, o número de contribuições apontadas pelos coordenadores superou o número de dificuldades relacionadas às avaliações.

Por fim, apesar de restrita a um município e a uma parcela dos coordenadores pedagógicos da rede municipal de educação de Indaiatuba, acreditamos que nossa pesquisa indica uma tendência de reorganização do trabalho das escolas e de seus profissionais em função das avaliações externas. Nessa 
perspectiva, consideramos necessária a realização de pesquisas que abranjam uma amostra expressiva de redes de ensino e unidades escolares, de forma que os resultados possam ser generalizáveis para um determinado estado ou para o país, permitindo evidenciar e analisar influências e/ou impactos das avaliações externas na organização do trabalho escolar e dos profissionais das escolas, visando contribuir para o debate em torno dessas avaliações. 


\title{
The centrality of the pedagogical coordinator in dealing with external evaluations - the Indaiatuba \\ case
}

\begin{abstract}
The article examines the centrality pedagogical coordinators have been acquiring in articulating external evaluations to perform their duties in municipal schools in Indaiatuba, corroborating researches related to assignments consecrated to pedagogical coordination. The text is derived from a master's degree research completed in 2011 which identified the town's educational management view of the coordinators' role concerning the evaluations, through the analysis of the Statute of the Professorship and interviews. Development actions made by the teaching network were identified, aimed at coordinators focused on evaluations, as well as monitoring actions on the professional's work. Moreover, opinions from pedagogical coordinators themselves about the subject were detected, showing the significant influence they had on their work.
\end{abstract}

Key words: Pedagogical coordinator. External evaluations. Pedagogical management. 


\section{REFERÊNCIAS}

ARCAS, P. H. Implicações da progressão continuada e do Saresp na avaliação escolar: tensões, dilemas e tendências. 89 f. Tese (Doutorado em Educação) Faculdade de Educação da Universidade de São Paulo, São Paulo, 2009.

BONAMINO, A.; F., Creso. Avaliação e política educacional: o processo de institucionalização do Saeb. Cadernos de Pesquisa, São Paulo, n. 108, p. 101132, nov. 1999.

BRASIL/MEC. Plano de Desenvolvimento da Educação: PDE/Saeb: ensino médio: matrizes de referência, tópicos e descritores. Brasília: MEC/SEB/Inep, 2008.

BRESSER PEREIRA, L. C. Reforma do estado para a cidadania: a reforma gerencial brasileira na perspectiva internacional. 1. ed. Brasília: Enap; São Paulo: Editora 34, 1998.

ESQUINSANI, R. S. S. Tá lá, em cima da mesa: os dados das avaliações em larga escala e a mediação do coordenador pedagógico. In: WERLE, Flávia Obino Corrêa. Avaliação em larga escala: foco na escola. 1. ed. Brasília: Líber Livro, 2010, p. 134-146.

FCC; FVC. O coordenador pedagógico e a formação de professores: intenções, tensões e contradições. São Paulo: Abril, 2011. 135 p. (Estudos e Pesquisas Educacionais).

FERRAROTTO, L. Promase: análise de uma experiência de avaliação do sistema municipal de ensino de Amparo. 86 f. Dissertação (Mestrado em Educação) - Faculdade de Educação da Universidade Estadual de Campinas (Unicamp), Campinas, 2011.

INDAIATUBA. Decreto $\mathrm{n} \mathbf{0} \mathbf{9 . 7 2 4}$, de $\mathbf{2 8}$ de março de 2008. Regulamenta a concessão de Gratificação de Produção e Aperfeiçoamento Profissional - GPAP, na área educacional, prevista no art. 25 da Lei no 4.309, de 2 de abril de 2003, alterado pela Lei no 5.273 , de 6 de fevereiro de 2008 e dá outras providências.

Lei complementar $\mathrm{n}^{\mathbf{0}} \mathbf{7}$, de 5 de janeiro de 2009. Dispõe sobre 0 Estatuto, Plano de Carreira e Remuneração do Magistério Público do Município, e dá outras providências. 
NEVO, D. Evaluation in education. In: SHAW, Ian F.; GREENE, Jennifer C.; MARK, Melvin M. Handbook of evaluation: policies, programs and practices. London: Sage Publications, 2006, p. 441-460.

OLIVEIRA, R. P. Avaliações externas podem auxiliar o trabalho pedagógico da escola? In: SECRETARIA MUNICIPAL DE EDUCAÇÃO/SÃO PAULO - DIRETORIA DE ORIENTAÇÃO TÉCNICA (Org.). Educação: fazer e aprender na cidade de São Paulo. São Paulo: Fundação Padre Anchieta/SME-SP, v. 1, p. 230-237, 2008.

OVANDO, N. G. A avaliação na política educacional de municípios sul-matogrossenses. 127 p. Dissertação (Mestrado em Educação) - Faculdade de Educação da Universidade Federal da Grande Dourados, Dourados, 2011.

RIBEIRO, S. C. A pedagogia da repetência. Estudos Avançados, São Paulo, v. 5, n. 12, p. 7-21, 1991.

SECRETARIA DA EDUCAÇÃO BÁSICA DO CEARÁ (SEE/CE). A gestão pedagógica e o desempenho escolar. Fortaleza: Edições Seduc, 2005.

SILVA, M. J. A. Regulação educativa: o uso de resultados de proficiência de avaliações do Proeb por diretores escolares em Minas Gerais. 121 f. Tese (Doutorado em Educação). Faculdade de Educação da Universidade Federal de Minas Gerais, Belo Horizonte, 2011.

SOUSA, S. M. Z. L. Avaliação do rendimento escolar como instrumento de gestão educacional. In: OLIVEIRA, D. A. Gestão democrática da educação: desafios contemporâneos. Petrópolis: Vozes, 1997, p. 264-283.

; OLIVEIRA, R. P. Políticas de avaliação e quase mercado no Brasil. Educação e Sociedade, São Paulo, v. 24, n. 84, p. 873-895, set. 2003.

. Avaliação e gestão da educação básica. In: DOURADO, Luiz. Políticas e gestão da educação no Brasil: novos marcos regulatórios. São Paulo: Xamã, 2009, p. 31-45.

VIANNA, H. M. Avaliações nacionais em larga escala: análise e propostas. v. 23. São Paulo: DPE/FCC, 2003. 41 p. (Textos FCC, 23)

RECEBIDO: Agosto de 2013.

APROVADO: Setembro de 2013. 